\title{
Uso da plasticidade morfológica como estratégia para a redução da população de plantas em cultivares de soja
}

\section{Plasticity morphologic use as a strategy for plant population reduction in soybean cultivars}

\section{Cristiano Büchling ${ }^{1}$, Antonio Mendes de Oliveira Neto ${ }^{2 *}$, Naiara Guerra ${ }^{3}$, Eduardo Leonel Bottega ${ }^{4}$}

\author{
${ }^{1}$ Faculdade Integrado de Campo Mourão, PR, Brasil. \\ ${ }^{2}$ Instituto Federal Catarinense (IFC), campus de Rio do Sul, SC, Brasil. Estrada do Redentor, 5665 - Cx. Postal \\ 441 - CEP 89163-356 - Rio do Sul, SC. E-mail:<am.oliveiraneto@gmail.com>. \\ ${ }^{3}$ Universidade Federal de Santa Catarina (UFSC), Centro de Curitibanos, SC, Brasil. \\ ${ }^{4}$ Universidade Federal de Santa Maria (UFSM), Campus de Cachoeira do Sul, RS, Brasil.
}

\section{Recebido em: 26/03/2015}

Aceito em:04/04/2017

\begin{abstract}
Resumo: A produtividade de uma cultura é definida pela interação entre a planta, o ambiente de produção e o manejo. Dentre as práticas de manejo está a época de semeadura, a escolha da cultivar, o espaçamento e a população de plantas. Desta forma, o objetivo deste trabalho foi avaliar a influência da população de plantas sobre a produtividade de grãos de nove cultivares de soja, em duas localidades, Campo Mourão - PR e Passo Fundo - RS. O delineamento experimental utilizado foi de blocos casualizados, organizados em esquema fatorial $4 \times 9$, com três repetições. Os experimentos foram conduzidos em área experimental, localizados nos municípios de Campo Mourão - PR e Passo Fundo - RS. O período de condução foi de Outubro 2011 a Abril de 2012. A densidade de semeadura foi avaliada em quatro níveis $\left(150,250,350,450\right.$ mil plantas ha $\left.{ }^{-1}\right)$. O segundo fator consistiu de nove cultivares de soja (Fepagro 36 RR; Fepagro 37 RR; FPS Iguaçu RR; FPS Júpiter RR; FPS Netuno RR; FPS Paranapanema RR; FPS Solimões RR; BRS Tordilha RR; FPS Urano RR). Ao final do ciclo avaliou-se a produtividade de grãos. A produtividade de grãos de soja foi pouco influenciada pela população de plantas avaliada. A cultivar FPS Júpiter RR e BRS Tordilha RR bem como FPS Netuno RR e FPS Urano RR se destacaram para valor de altos rendimentos nas regiões de Campo Mourão e Passo Fundo, respectivamente.
\end{abstract}

Palavras-chave: Glycine max, interação genótipo x ambiente, fitotecnia, rendimento

Abstract: Crop grain yield was define for plant, environmental and management interaction. Among the management practices are sowing time, cultivar chosen, spacing and plant population. Then, this work was the aim to evaluate the plant population influence on the grain yield of nine soybean cultivars, in two localities, Campo Mourão - PR and Passo Fundo - RS. The experimental design was block completely randomized, organized in factorial scheme $4 \times 9$, with three replications. The experiments were conduct in Campo Mourão - PR and Passo Fundo - RS. The period of conduct was October 2011 to April 2012. The sowing density evaluated were 150, 250, 350 and 450 thousands plants ha ${ }^{-1}$. The second factor constituted for nine soybean cultivars (Fepagro 36 RR; Fepagro 37 RR; FPS Iguaçu RR; FPS Júpiter RR; FPS Netuno RR; FPS Paranapanema RR; FPS Solimões RR; BRS Tordilha RR; FPS Urano RR). In the end of the cycle was evaluated the grain yield. The grain yield was little influence for plant population. The cultivars FPS Júpter RR and BRS Tordilha RR as well as FPS Netuno RR and FPS Urano RR stood out for high grain yield in Campo Mourão and Passo Fundo, respectively.

Keywords: Glycine max, genotype x environment interaction, crop science, grain yield

\section{Introdução}

A soja é uma das principais espécies cultivadas pelo homem, devido ao seu bom potencial produtivo, composição química e alto valor nutritivo, que lhe confere múltiplos usos, como na alimentação humana, animal e na produção de biocombustíveis. Desta forma, a soja se tornou uma matéria prima indispensável para diversos complexos agroindustriais e assumiu um papel socioeconômico relevante (Mauad et al., 2010 e Silva et al., 2010). 


\section{(2) \\ Revista Agrarian \\ ISSN: 1984-2538}

Para atingir elevados rendimentos, as cultivares dependem das condições do ambiente de produção em que as plantas irão se desenvolver (Wells, 1991). Assim, alterações relacionadas ao arranjo de plantas podem reduzir ou aumentar a produtividade de grãos, por afetar a interceptação da radiação fotossinteticamente ativa, a capacidade fotossintética do dossel e a respiração do dossel (Motta et al, 2000; Argenta et al., 2001; Heiffig et al., 2006 e Mattioni et al., 2008).

A população é um dos fatores que compõe o arranjo das plantas e influencia diretamente no crescimento da cultura da soja (Martins et al., 1999). Este parâmetro interfere na competição inter e intraespecífica por recursos do meio e pode provocar mudanças morfofisiológicas nas plantas (Argenta et al., 2001 e Heiffig et al., 2006).

A soja apresenta características de alta plasticidade de resposta ao arranjo espacial de plantas, ou seja, possui grande capacidade de se adaptar ao ambiente produtivo e ao manejo adotado, alterando sua morfologia e seus componentes de produção (Heiffig-del Aguila et al., 2005; Ferreira Junior et al., 2010 e Silva et al., 2010). Trabalhos realizados por Peixoto et al. (1999) e Mauad et al. (2010), demonstram que as plantas de soja compensam baixas populações de plantas com o aumento no número de nós reprodutivos, de vagens e de grãos por vagem.

Nas últimas safras as cultivares de soja sofreram alterações expressivas quanto ao tipo de crescimento, ciclo e arquitetura de plantas. Essas alterações ocorreram para facilitar o manejo fitossanitário da cultura, favorecendo a deposição de agroquímicos sobre os alvos localizados na parte interna das plantas, além de proporcionar um ambiente menos favorável ao desenvolvimento de fungos fitopatogênicos. Contudo, essas alterações morfofisiológicas podem exigir alterações no arranjo das plantas. Estudos sugeriram que as cultivares de crescimento indeterminado apresentam máxima produtividade com densidade de plantas superior às cultivares de crescimento determinado (Egli, 1988).

A partir do exposto, formulou-se a hipótese de que há a possibilidade de reajustar a população de plantas nos cultivares de soja atuais, principalmente fazendo uso de populações menores, sem prejuízos ao rendimento de grãos. Para isso conduziu-se dois experimentos com o objetivo de avaliar a influência de diferentes populações de plantas sobre a produtividade de grãos de nove cultivares de soja, em dois ambientes de produção, localizados nos município de Campo Mourão - PR e Passo Fundo - RS.

\section{Material e métodos}

Os experimentos foram conduzidos em áreas experimentais, localizadas nos municípios de Passo Fundo - RS e Campo Mourão - PR. A localização geográfica dos campos experimentais, são, respectivamente, $28^{\circ} 12^{\prime} 46^{\prime \prime}$ de latitude Sul; $52^{\circ} 21^{\prime} 12^{\prime \prime}$ longitude Oeste e $24^{\circ} 01^{\prime} 02^{\prime \prime}$ de latitude Sul; 52 $19^{\prime} 06^{\prime \prime}$ de longitude Oeste. O solo de ambos os locais é classificado como Latossolo Vermelho distroférico (Embrapa, 2013). A altitude média do campo experimental em Passo Fundo é de $700 \mathrm{~m}$ e em Campo Mourão $580 \mathrm{~m}$. Em ambas as localidades o clima é classificado, segundo Köppen, como Cfa (Ritta Neto, 2010). Os experimentos foram conduzidos de Outubro 2011 a Abril de 2012, os valores de precipitação observado durante o período de condução dos experimentos estão apresentados na Figura 1.

A correção do solo e a adubação das áreas foram feitas de acordo com os resultados das análises de solo, em concordância com as recomendações para a cultura da soja (Sfredo, 2008) sendo aplicado por ocasião da semeadura $350 \mathrm{~kg} \mathrm{ha}^{-1}$ de N P K, na formulação 2-20-20, na área de Passo Fundo e $63 \mathrm{~kg} \mathrm{P}_{2} \mathrm{O}_{5}$ ha $^{-1}$ (superfosfato simples) $+72 \mathrm{~kg} \mathrm{~K}_{2} \mathrm{O}$ ha $^{-1}$ (cloreto de potássio) em cobertura, para área de Campo Mourão. 


\section{(a) \\ Revista Agrarian \\ ISSN: 1984-2538}

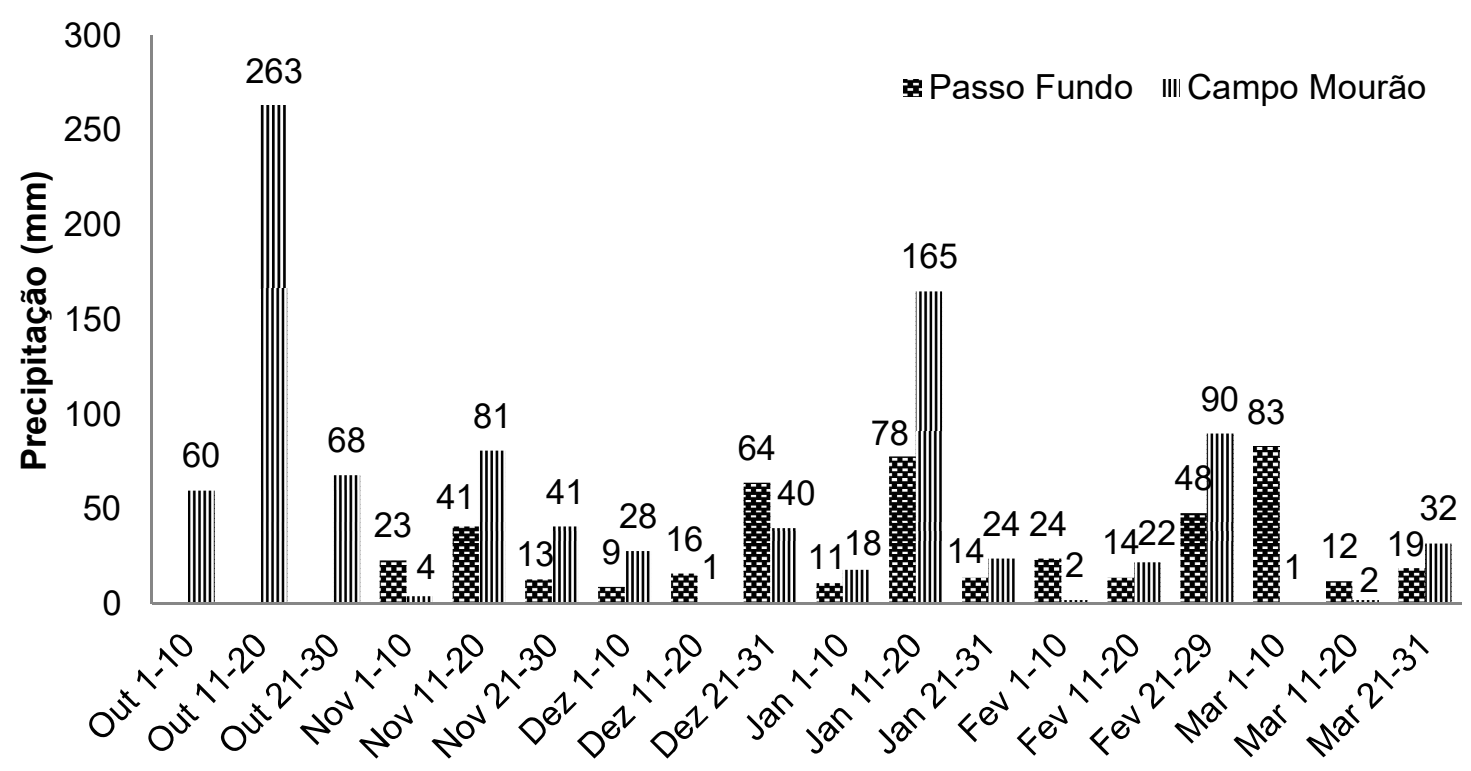

Figura 1. Precipitação (mm) entre os meses de outubro de 2011 e março de 2012 para os municípios de Campo Mourão - PR e Passo Fundo - RS.

O delineamento experimental foi de blocos casualizados em arranjo fatorial $4 \times 9$, com três repetições. O primeiro fator consistiu de quatro níveis de população de plantas $(150,250,350,450$ mil plantas $\mathrm{ha}^{-1}$ ), enquanto o segundo fator foi representado por nove cultivares de soja (Fepagro 36 RR; Fepagro 37 RR; FPS Iguaçu RR; FPS Júpiter RR; FPS Netuno RR; FPS Paranapanema RR; FPS Solimões RR; BRS Tordilha RR; FPS Urano RR), totalizando 36 tratamentos distribuídos em 108 parcelas. Cada parcela foi composta por 5 linhas de 4 metros de comprimento, espaçadas em
0,45 m $\left(9,0 \mathrm{~m}^{2}\right)$. A descrição de cada cultivar avaliada encontra-se na Tabela 1 .

Antes da semeadura as sementes foram tratadas com fungicida e inseticida, Standak Top ${ }^{\circledR}$, na dose de $200 \mathrm{~mL}$ (p.c.) para cada $100 \mathrm{~kg}$ de sementes. A semeadura foi realizada mecanicamente, com uma semeadora-adubadora de parcelas, em sistema de semeadura direta. Incrementou-se em $10 \%$ a quantidade de sementes distribuídas por metro de linha, após a emergência, as plantas foram desbastadas buscando a obtenção da população desejada em cada tratamento.

Tabela 1. Relação das cultivares de soja, tipo de crescimento e grupo de maturação que foram avaliadas nos experimentos conduzidos em Campo Mourão - PR e Passo Fundo - RS.

\begin{tabular}{ccc}
\hline Cultivares & Tipo de crescimento & Grupo de maturação \\
\hline Fepagro 36 RR & Determinado & 7.1 \\
Fepagro 37 RR & Determinado & 6.1 \\
FPS Iguaçu RR & Indeterminado & 5.0 \\
FPS Júpiter RR & Indeterminado & 5.9 \\
FPS Netuno RR & Indeterminado & 6.3 \\
FPS Paranapanema RR & Indeterminado & 5.9 \\
FPS Solimões RR & Indeterminado & 5.7 \\
BRS Tordilha RR & Determinado & 6.2 \\
FPS Urano RR & Determinado & 6.2 \\
\hline
\end{tabular}

Obs: informações disponibilizadas pelos obtentores.

A semeadura foi realizada respeitando o calendário de cada região edáfica, sendo realizada em 13/10/2012 em Campo Mourão - PR e em 05/11/2012 em Passo Fundo. O experimento foi

Büchling et al., v.10, n.35, p. 22-30, Dourados, 2017 


\section{(ㅇ) \\ Revista Agrarian \\ ISSN: 1984-2538}

monitorado com relação às plantas daninhas, insetos e doenças sendo o manejo fitossanitário realizado conforme as recomendações técnicas para a cultura da soja (Reunião, 2010).

As plantas foram colhidas mecanicamente, cinco a oito dias após o estádio fenológico R8, ou seja, quando $95 \%$ das vagens apresentaram-se com coloração típica de vagem madura. Para a colheita, foi utilizada uma colhedora de parcelas. A colheita foi realizada desprezando-se as duas linhas externas, totalizando uma área útil de $5,4 \mathrm{~m}^{2}$.

O beneficiamento das sementes de cada parcela consistiu na passagem destas na máquina de pré-limpeza específica para amostras de experimentos, onde efetuou-se a separação de impurezas contidas nas amostras. Após a limpeza, foram realizadas as avaliações finais de produtividade. A umidade foi corrigida para $130 \mathrm{~g}$ $\mathrm{kg}^{-1}$, em todas as unidades experimentais.

Os dados obtidos em cada experimento foram individualmente submetidos à análise de variância pelo teste $\mathrm{F}$, sendo o fator quantitativo população de plantas submetido à análise de regressão polinomial e o fator qualitativo cultivar submetido ao teste de Scott-Knott (Scott \& Knott, 1974). Como os experimentos tinham estrutura comum, realizou-se a análise conjunta dos dados, visando à obtenção de conclusões mais abrangentes. Para isso, adotou-se fatores físicos em comum (tipo de solo, topografia e manejo), mesmo ano agrícola e obedecendo a ordem de grandeza dos quadrados médios residuais das análises individuais (Banzatto \& Kronka, 2006). Em todas as análises o nível de probabilidade adotado foi de $5 \%(\mathrm{p}<0,05)$. Todas as análises foram realizadas com o auxílio do programa estatístico Sisvar (Ferreira, 2011).

\section{Resultados e discusão Análise individual}

A produtividade de grãos das cultivares Fepagro 36 RR, Fepagro 37 RR, FPS Júpiter RR, FPS Paranapanema RR e FPS Solimões não foi influenciada de maneira significativa, em função da população de plantas, nas duas localidades. No município de Campo Mourão a produtividade média dessas cultivares foi de $3.415,5 ; 4.425,0$; $4.889,8 ; \quad 4.128,4$ e $4.115,9 \quad \mathrm{~kg} \quad \mathrm{ha}^{-1}$, respectivamente. Já em Passo Fundo a produtividade média foi de respectivamente,
$2.256,8 ; 2.604,5 ; 2.628,7 ; 2.354,1$ e $2.279,4 \mathrm{~kg} \mathrm{ha}^{-}$

1 (dados não apresentados).

Uma das justificativas destes resultados seria a alta capacidade dessas cultivares alterarem a sua morfologia com a variação na densidade de plantas, ajustando os componentes de produção (número de ramificações, de nós reprodutivos, de vagens e de grãos por $\mathrm{m}^{2}$ ) e mantendo a estabilidade de rendimento. Essa capacidade da soja em ajustar os componentes de produção conforme a área disponível ao crescimento já foi descrita por Heiffig-del Aguila et al. (2005) e Mauad et al. (2010)

Contudo, os resultados de produtividade em função da densidade de semeadura são contraditórios. Enquanto Nakagawa et al. (1986) e Heiffig-del Aguila et al. (2005) não observaram efeito significativo, Peixoto et al. (1999), Tourino et al. (2002) e Heiffig et al. (2006) observam aumento de rendimento em função do aumento da densidade de semeadura.

Neste estudo, constatou-se que estas cultivares apresentaram a capacidade de manter a produtividade de grãos estável com a alteração na população de plantas em duas macrorregiões sojícolas diferentes (102 e 201).

Para as cultivares FPS Iguaçu RR, FPS Netuno, BRS Tordilha RR e FPS Urano RR observou-se efeito significativo da população de plantas na produtividade de grãos, em pelo menos uma das localidades avaliadas (Figura 2). Em Passo Fundo, as cultivares FPS Netuno RR e BRS Tordilha RR apresentaram decréscimo de produtividade quando se aumentou a população de plantas de 150 para 250 e 350 mil plantas por ha- ${ }^{-1}$. Essas mesmas cultivares apresentaram resultados distintos em Campo Mourão, pois mantiveram a produtividade média de grãos em todas as densidades. Assim, podemos constatar que essas cultivares conseguiram modificar suas características fenotípicas de maneira mais eficiente em Campo Mourão.

As cultivares que apresentaram aumento significativo da produtividade com o aumento da densidade de semeadura, foram FPS Iguaçu RR e a FPS Urano RR na região de Campo Mourão e Passo Fundo, respectivamente. Esses foram os únicos genótipos que responderam positivamente ao incremento de população. Entretanto, constatouse que a magnitude da resposta foi baixa em ambas as situações, já que o coeficiente angular da reta foi 


\section{Revista Agrarian}

ISSN: 1984-2538

de 2,14 para a cultivar FPS Iguaçu RR em Campo Mourão e 1,33 para cultivar FPS Urano RR em Passo Fundo. Desta forma, antes da decisão de aumentar a densidade de semeadura, deveria se realizar uma criteriosa análise de viabilidade econômica. Heiffig et al. (2006) relataram crescimento proporcional da produtividade com o aumento da população de plantas da cultivar
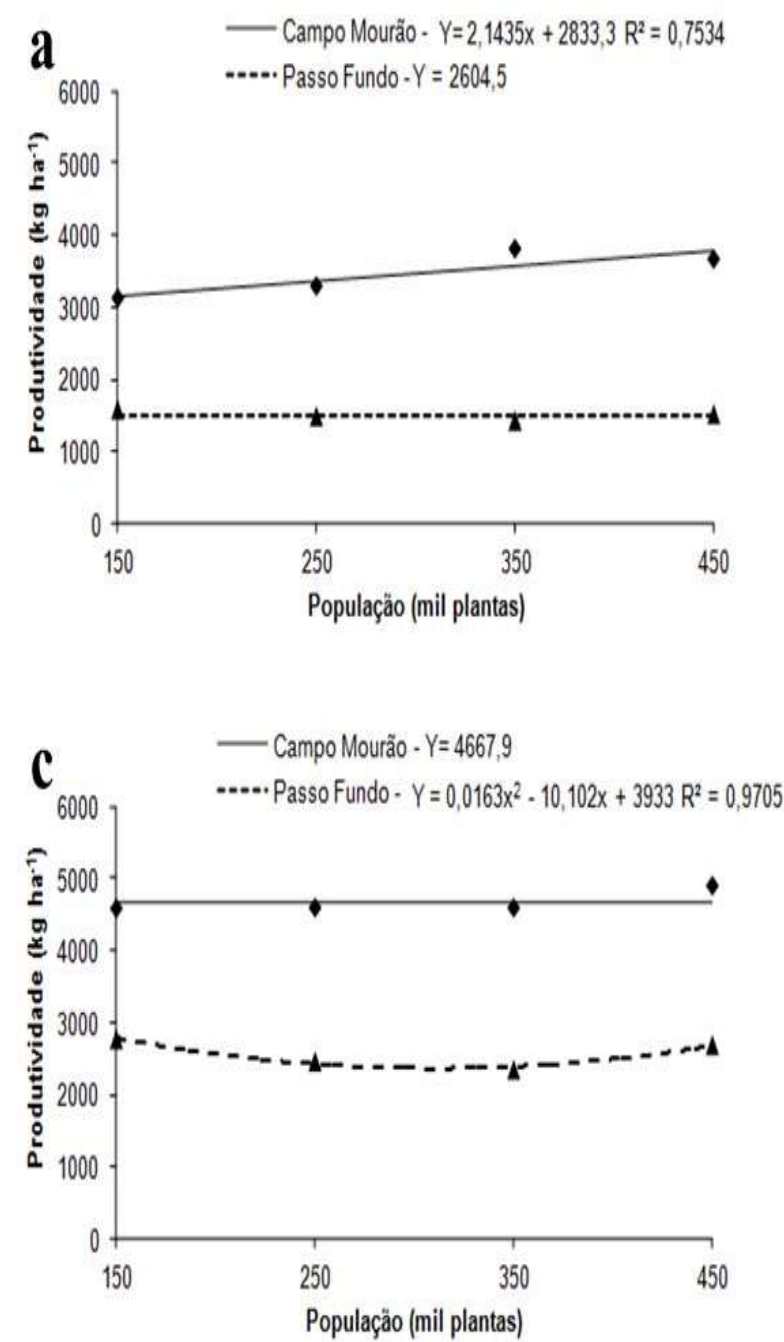

MG/BR - 46 (Conquista), conduzida no município de Piracicaba.

De maneira geral, observou-se menor resposta das cultivares a variação de população de plantas no município de Campo Mourão do que em Passo Fundo, já que das nove cultivares avaliadas, apenas a FPS Iguaçu RR apresentou resposta significativa.
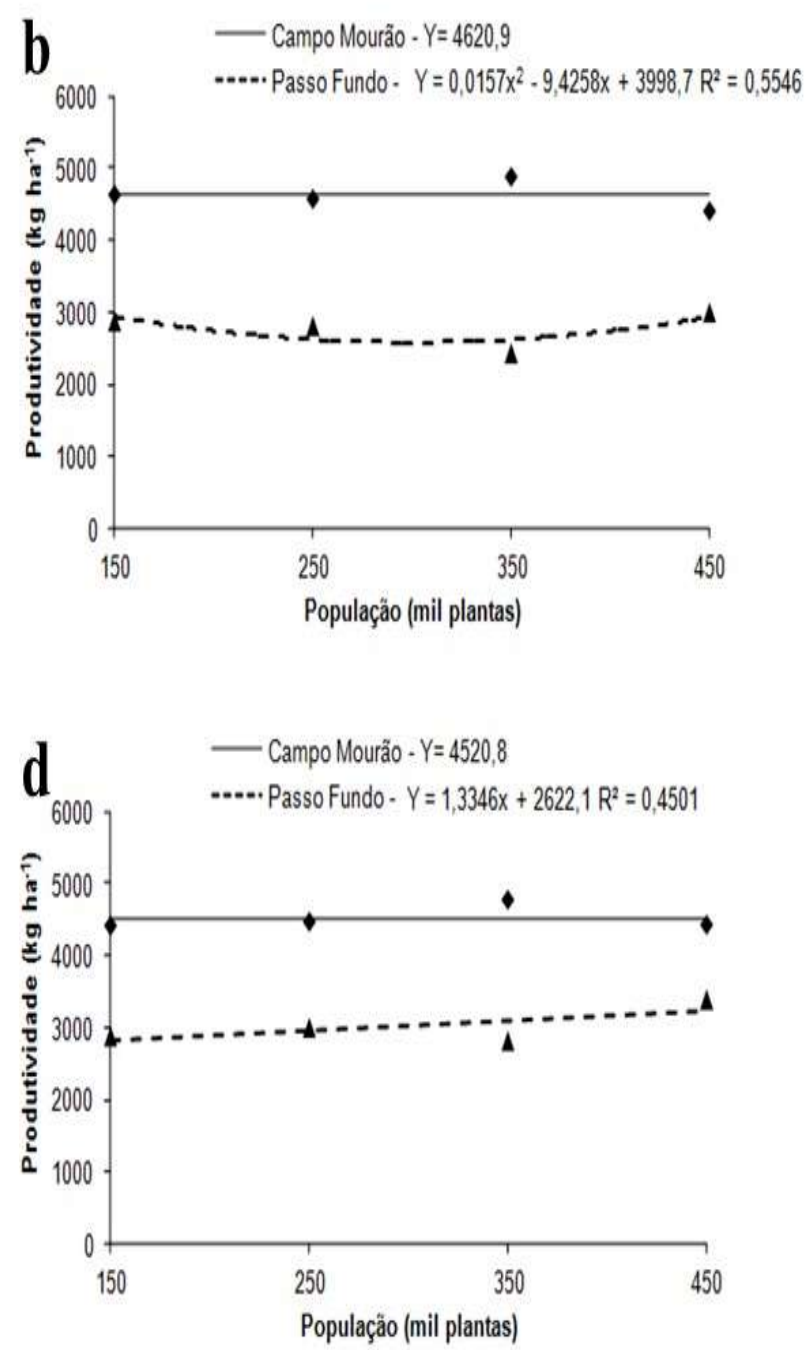

Figura 2. Produtividade de grãos $\left(\mathrm{kg} \mathrm{ha}^{-1}\right)$ das cultivares FPS Iguaçu RR (a), FPS Netuno RR (b), BRS Tordilha RR (c) e FPS Urano RR (d) em função da população de plantas para os municípios de Campo Mourão - PR e Passo Fundo - RS.

A análise das cultivares submetida a diferentes populações de plantas, no município de Campo Mourão, demonstrou que as cultivares FPS Júpiter RR e BRS Tordilha RR se destacaram com maior produtividade (Tabela 2). Notou-se uma grande estabilidade produtiva dessas cultivares em todas as situações estudadas.
As cultivares Fepagro 36 RR e FPS Iguaçu $\mathrm{RR}$ se destacaram pela baixa produtividade de grãos, além da diferença entre as densidades. A estabilidade de uma cultivar está relacionada com o ambiente e o manejo com que ela é conduzida. Desse modo podemos verificar que nem todas as cultivares apresentaram essas características. Tal comportamento também pode ser explicado pelas

Büchling et al., v.10, n.35, p. 22-30, Dourados, 2017 


\section{Revista Agrarian}

ISSN: 1984-2538

características da região que a cultivar se desenvolveu, pois é comum apresentar diferença de rendimento entre regiões (Godoi et al., 2005). No caso dessas cultivares, o grupo de maturação não são os mais indicados para Campo Mourão, sendo Fepagro 36 RR de ciclo muito tardio (7.0) e FPS Iguaçu de ciclo muito precoce (5.0).

Tabela 2. Produtividade de grãos $\left(\mathrm{kg} \mathrm{ha}^{-1}\right)$ de cultivares de soja submetida a diferentes populações de plantas no município de Campo Mourão. Campo Mourão - PR.

\begin{tabular}{|c|c|c|c|c|c|c|c|c|}
\hline \multirow{3}{*}{ Cultivares } & \multicolumn{8}{|c|}{ Produtividade $\left(\mathrm{kg} \mathrm{ha}^{-1}\right)$} \\
\hline & \multicolumn{8}{|c|}{ População (mil plantas) } \\
\hline & \multicolumn{2}{|c|}{150} & \multicolumn{2}{|c|}{250} & \multicolumn{2}{|l|}{350} & \multicolumn{2}{|c|}{450} \\
\hline Fepagro $36 \mathrm{RR}$ & 3259,6 & $\mathrm{c}$ & 3368,3 & $\mathrm{~b}$ & 3573,0 & $\mathrm{c}$ & 3457,0 & $\mathrm{c}$ \\
\hline Fepagro $37 \mathrm{RR}$ & 4513,3 & $\mathrm{a}$ & 4202,0 & $\mathrm{a}$ & 4441,3 & $\mathrm{a}$ & 4543,6 & $\mathrm{~b}$ \\
\hline FPS Iguaçu RR & 3128,3 & $\mathrm{c}$ & 3294,3 & $\mathrm{~b}$ & 3812,6 & $\mathrm{~b}$ & 3670,0 & $\mathrm{c}$ \\
\hline FPS Júpiter RR & 4972,0 & $\mathrm{a}$ & 4567,0 & $\mathrm{a}$ & 5001,6 & $\mathrm{a}$ & 5018,3 & $\mathrm{a}$ \\
\hline FPS Netuno RR & 4630,6 & $\mathrm{a}$ & 4571,6 & $\mathrm{a}$ & 4878,6 & $\mathrm{a}$ & 4402,6 & $\mathrm{~b}$ \\
\hline FPS Paranapanema RR & 3960,0 & $\mathrm{~b}$ & 4057,6 & $\mathrm{a}$ & 4318,0 & $\mathrm{a}$ & 4177,6 & $\mathrm{~b}$ \\
\hline FPS Solimões RR & 3777,0 & $\mathrm{~b}$ & 4225,0 & $\mathrm{a}$ & 4200,0 & $\mathrm{~b}$ & 4261,6 & $\mathrm{~b}$ \\
\hline BRS Tordilha RR & 4584,3 & $\mathrm{a}$ & 4595,3 & $\mathrm{a}$ & 4591,6 & $\mathrm{a}$ & 4900,3 & $\mathrm{a}$ \\
\hline FPS Urano RR & 4415,6 & $\mathrm{a}$ & 4467,6 & $\mathrm{a}$ & 4773,3 & $\mathrm{a}$ & 4426,3 & $\mathrm{~b}$ \\
\hline CV $(\%)$ & & & & & & & & \\
\hline
\end{tabular}

Médias seguidas de mesma letra na coluna não diferem entre si pelo teste de Skott-Knott, a 5\% de probabilidade.

Houve um resultado distinto para região de Passo Fundo, para a produtividade de grãos (Tabela 3). As cultivares FPS Urano RR e FPS Netuno RR foram as que se destacaram com as melhores produtividades, em todas as populações testadas. Já com o menor desempenho se destacou a cultivar FPS Iguaçu RR, com baixa produtividade em todas as densidades.

Tabela 3. Produtividade de grãos $\left(\mathrm{kg} \mathrm{ha}^{-1}\right)$ de cultivares de soja submetida a diferentes populações de plantas no município de Passo Fundo - RS.

\begin{tabular}{|c|c|c|c|c|c|c|c|c|}
\hline \multirow{3}{*}{ Cultivares } & \multicolumn{8}{|c|}{ Produtividade $\left(\mathrm{kg} \mathrm{ha}^{-1}\right)$} \\
\hline & \multicolumn{8}{|c|}{ População (mil plantas) } \\
\hline & 150 & & 250 & & 350 & & 450 & \\
\hline Fepagro 36 RR & 2285,3 & $\mathrm{~b}$ & 2325,0 & $\mathrm{~b}$ & 2258,0 & $\mathrm{a}$ & 2559,0 & $\mathrm{~b}$ \\
\hline Fepagro $37 \mathrm{RR}$ & 2637,3 & $\mathrm{a}$ & 2550,0 & $\mathrm{~b}$ & 2453,0 & $\mathrm{a}$ & 2777,6 & $\mathrm{~b}$ \\
\hline FPS Iguaçu RR & 1582,0 & $\mathrm{c}$ & 1493,0 & $\mathrm{c}$ & 1429,6 & $\mathrm{~b}$ & 1518,3 & $\mathrm{~d}$ \\
\hline FPS Júpiter RR & 2450,0 & $\mathrm{~b}$ & 2786,3 & $\mathrm{a}$ & 2329,3 & $\mathrm{a}$ & 2949,0 & $\mathrm{a}$ \\
\hline FPS Netuno RR & 2875,0 & $\mathrm{a}$ & 2811,6 & $\mathrm{a}$ & 2433,3 & $\mathrm{a}$ & 2997,6 & $\mathrm{a}$ \\
\hline FPS Paranapanema RR & 2296,6 & $\mathrm{~b}$ & 2319,6 & $\mathrm{~b}$ & 2251,6 & $\mathrm{a}$ & 2548,3 & $\mathrm{~b}$ \\
\hline FPS Solimões RR & 2275,6 & $\mathrm{~b}$ & 2187,0 & $\mathrm{~b}$ & 2389,3 & $\mathrm{a}$ & 2265,6 & $\mathrm{c}$ \\
\hline BRS Tordilha RR & 2770,6 & $\mathrm{a}$ & 2463,3 & $\mathrm{~b}$ & 2351,0 & $\mathrm{a}$ & 2694,3 & $\mathrm{~b}$ \\
\hline FPS Urano RR & 2883,0 & $\mathrm{a}$ & 3001,6 & $\mathrm{a}$ & 2815,3 & $\mathrm{a}$ & 3390,0 & $\mathrm{a}$ \\
\hline
\end{tabular}

Médias seguidas de mesma letra na coluna não diferem entre si pelo teste de Scott-Knott, a 5\% de probabilidade.

Para estado do Rio Grande do Sul, Ludwig et al. (2007), recomendaram uma população de 350 mil plantas $\mathrm{ha}^{-1}$, o que está de acordo com os resultados obtidos, onde a maior estabilidade de rendimento das cultivares se deu dentro da densidade de 350 mil plantas ha-1.

\section{Análise conjunta}

Em relação aos dois locais estudados, foi possível identificar que na região de Campo Mourão houve produtividade de grãos superior a Passo Fundo, para todas as cultivares (Tabela 4). No entanto, destaca-se que durante o desenvolvimento da cultura em Passo Fundo, a precipitação total acumulada foi de $387 \mathrm{~mm}$ (Figura 


\section{(ㄱ) \\ Revista Agrarian \\ ISSN: 1984-2538}

1). Trabalhos de Matzenauer et al. (2003) relataram que a necessidade total de água na cultura da soja, para obtenção do máximo rendimento, varia entre 450 a $800 \mathrm{~mm}$ por ciclo, dependendo das condições climáticas, do manejo da cultura e da duração do ciclo, o que justifica a baixa produtividade apresentada em Passo Fundo. A disponibilidade de água é importante, principalmente, em dois períodos de desenvolvimento da soja: germinação- emergência e floração- enchimento de grãos. Os valores de precipitação nesses estádios foram críticos, não alcançando a média de 7 a $8 \mathrm{~mm} \mathrm{dia}^{-1}$, que a soja necessita para assegurar o potencial produtivo. Em Campo Mourão a precipitação acumulada durante desenvolvimento da cultura somou $881 \mathrm{~mm}$, o que garantiu a expressão do potencial produtivo das cultivares.

Tabela 4. Produtividade de grãos $\left(\mathrm{kg} \mathrm{ha}^{-1}\right)$ de nove cultivares de soja nos municípios de Campo Mourão - PR e Passo Fundo - RS.

\begin{tabular}{|c|c|c|c|}
\hline \multirow{3}{*}{ Cultivares } & \multicolumn{3}{|c|}{ Produtividade $\left(\mathrm{kg} \mathrm{ha}^{-1}\right)$} \\
\hline & \multicolumn{3}{|c|}{ Município } \\
\hline & Campo Mourão & \multicolumn{2}{|c|}{ Passo Fundo } \\
\hline Fepagro $36 \mathrm{RR}$ & 3414,5 Ad & 2356,8 & $\mathrm{Bc}$ \\
\hline Fepagro 37 RR & $4425,1 \quad \mathrm{Ab}$ & 2604,5 & $\mathrm{Bb}$ \\
\hline FPS Iguaçu RR & $3476,3 \mathrm{Ad}$ & 1505,8 & $\mathrm{Bd}$ \\
\hline FPS Júpiter RR & 4889,8 & 2628,7 & $\mathrm{Bb}$ \\
\hline FPS Netuno RR & 4620,9 & 2779,4 & $\mathrm{Bb}$ \\
\hline FPS Paranapanema RR & 4128,3 & 2354,1 & $\mathrm{Bc}$ \\
\hline FPS Solimões RR & 4115,9 & 2279,4 & $\mathrm{Bc}$ \\
\hline BRS Tordilha RR & 4667,9 & 2569,8 & $\mathrm{Bb}$ \\
\hline FPS Urano RR & 4520,8 & 3022,5 & $\mathrm{Ba}$ \\
\hline
\end{tabular}

Médias seguidas de mesma letra minúscula na coluna e maiúscula na linha não diferem entre si pelo teste de Scott-Knott, a $5 \%$ de probabilidade.

Dentre as cultivares que mais se destacaram nas duas localidades, está FPS Júpiter RR e a FPS Urano RR, em Campo Mourão e Passo Fundo, respectivamente. Já os resultados para cultivares FPS Iguaçu RR e Fepagro 36 RR ficaram entre as menores produtividades em ambas as localidades. Foi possível observar que nenhuma cultivar demonstrou o mesmo desempenho nas duas regiões estudadas.

O resultado de produtividade de grãos, da média das cultivares, em função da densidade de plantas, mostrou que a resposta foi linear positiva para o município de Campo Mourão (Figura 3), contudo, o coeficiente angular da reta foi baixo (a $=0,79)$. Heiffig-del Aguila et al. (2005), Silva et al. (2010) e Rodrigues et al. (2011), relataram que a população de plantas é o fator que menos afeta a produtividade da soja, desde que as plantas estejam distribuídas uniformemente na área, devido a característica de alta plasticidade fenotípica.

Em Passo Fundo, notou-se queda na produtividade de grãos de soja com o aumento da população de plantas, neste caso, a menor densidade de plantas (150 mil plantas ha $\left.{ }^{-1}\right)$ seria a mais indicada, na média das cultivares (Figura 3)

Os resultados indicam que em média, as cultivares apresentaram baixa ou nenhuma resposta produtiva ao aumento de população de plantas, sendo que a hipótese inicialmente formulada foi confirmada, de que é possível utilizar menores populações de plantas (150 mil plantas $\mathrm{ha}^{-1}$ ou cerca de 7 plantas emergidas por metro linear, em espaçamento de $0,45 \mathrm{~m})$ sem prejuízos significativos a produtividade. Esse resultado é bastante relevante, pois mostra a possibilidade redução de gastos na semeadura, sem comprometimento da rentabilidade econômica. Todavia, é importante reforçar que esses resultados são válidos para os ambientes e genótipos avaliados no presente estudo, e que antes da definição da densidade de semeadura o técnico deve considerar uma série de fatores, tais como: cultivar, ambiente (altitude, latitude, precipitação, temperatura e radiação solar), solo (características físicas, químicas e biológicas), infestação de plantas daninhas e incidência e severidade de doenças.. 


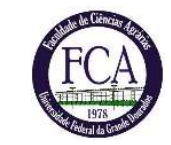

\section{Revista Agrarian}

ISSN: $1984-2538$

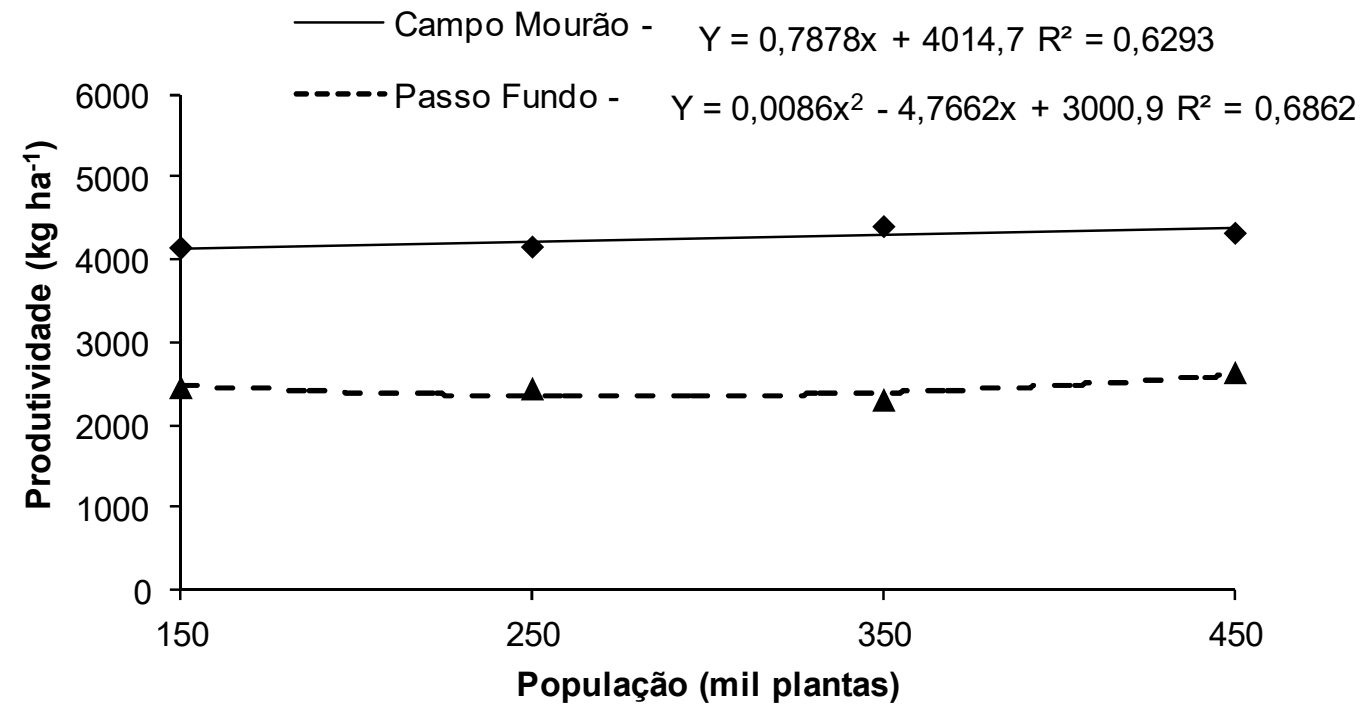

Figura 3. Média da produtividade de grãos $\left(\mathrm{kg} \mathrm{ha}^{-1}\right)$ de nove cultivares de soja em função da população de plantas, nos municípios de Campo Mourão - PR e Passo Fundo - RS

\section{Conclusões}

A produtividade de grãos de soja foi pouco influenciada pela população de plantas avaliada.

As cultivares FPS Júpiter RR e BRS Tordilha RR, bem como FPS Netuno RR e FPS Urano RR se destacaram pela boa produtividade nas regiões de Campo Mourão e Passo Fundo, respectivamente.

Todas as cultivares estudadas apresentaram produtividade superior quando cultivadas em Campo Mourão.

\section{Referências}

ARGENTA, G.; SILVA, P. R. F.; SANGOI, L. Arranjo de plantas em milho: análise do estado da arte. Ciência Rural, v. 31, n. 6, p. 1075-1084, 2001.

BANZATTO, D. A.; KRONKA, S. N. Experimentação Agrícola. 4. Ed. Jaboticabal: Funep, 2006.

EGLI, D. B. Plant density and soybean yield. Crop Science, v. 28, n. 6, p. 977-981, 1988.

EMBRAPA - Centro Nacional de Pesquisa de Solo. Sistema Brasileiro de Classificação de Solos. 3. Ed. Rio de Janeiro: Embrapa Solos, 2013.

FERREIRA JUNIOR, J. A.; ESPINDOLA, S. M. C. G.; GONÇALVES, D. A. R.; LOPES, E. W. Avaliação de genótipos de soja em diferentes épocas de plantio e densidade de semeadura no município de Uberaba - MG. Fazu em revista, v. 7, n. 7, p. 13-21, 2010.

FERREIRA, D.F. Sisvar: a computer statistical analysis system. Ciência e Agrotecnologia, v. 35, n. 6, p. 1039-1042, 2011.

GODOI, C. R. C.; SILVEIRA NETO, A. N.; PINHEIRO, J. B. Avaliação do desempenho de linhagens de soja, resistentes ao complexo de percevejos, cultivadas em diferentes densidades de semeadura. Bioscience Journal, v. 21, n. 1, p. 8593, 2005.

HEIFFIG, L. S.; CÂMARA, G. M. S.; MARQUES, L. A.; PEDROSO, D. B.; PIEDADE, S. M. S. Fechamento e índice de área foliar da cultura da soja em diferentes arranjos espaciais. Bragantia, v. 65, n.2, p. 285-295, 2006.

HEIFFIG-DEL AGUILA, L. S.; CÂMARA, G. M. S.; MARQUES, L. A.; PEDROSO, D. B.; PIEDADE, S. M. S. Plasticidade da cultura da soja (Glycine max (L.) Merrill) em diferentes arranjos espaciais. Revista de Agricultura, v. 80, n. 2, p. 188-212, 2005.

LUDWIG, M. P.; DUTRA, L. M. C.; ZABOT, L.; JAUER, A.; UHRY, D.; FARIAS, J. R.; LOSEKANN, M. E.; STEFANELO, C.; LUCCA FILHO, O. A. Efeito da densidade de semeadura e genótipos no rendimento de grãos e seus 


\section{(a) \\ Revista Agrarian \\ ISSN: 1984-2538}

componentes na soja semeada após a época indicada. Revista da FZVA, v.14, n. 2, p.13-22, 2007.

MARTINS, M. C.; CÂMARA, G. M. S.; PEIXOTO, C. P.; MARCHIORI, L. F. S.; LEONARDO, V.; MATTIAZZI, P. Épocas de semeadura, densidades de plantas e desempenho vegetativo de cultivares de soja. Scientia Agricola, v. 56, n. 4, p. 851-858, 1999.

MATTIONI, F.; CORRÊA, L. A. V.; GOMES, J. C. C.; WÜNCH, J. Arranjos espaciais, plantas concorrentes e características agronômicas da soja (Glycine max (Linn) Merril) em cultivo orgânico. Revista Brasileira de Agrociência, v. 14, n. 4, p. 21-32, 2008.

MATZENAUER, R.; BARNI, N. A.; MALUF, J. R. T. Estimativa do consumo relativo de água para a cultura da soja no Estado do Rio Grande do Sul. Ciência Rural, v. 33, n. 6, p. 1013-1019, 2003.

MAUAD, M.; SILVA, T. L. B.; ALMEIDA NETO, A. I.; ABREU, V. G. Influência da densidade de semeadura sobre as características agronômicas na cultura da soja. Agrarian, v. 3, n. 9, p. 175-181, 2010.

MOTTA, I. S.; BRACCINI, A. L.; SCAPIM, C. A.; GONÇALVES, A.C.A.; BRACINI, M.C.L. Características agronômicas e componentes da produção de sementes de soja em diferentes épocas de semeadura. Revista Brasileira de Sementes, v. 22, n. 2, p. 153-162, 2000.

NAKAGAWA, J.; MACHADO, J. R.; ROSELEM C. A. Efeito da densidade de plantas e da época de semeadura na produção e qualidade de sementes de soja. Revista Brasileira de Sementes, v. 8, n. 3, p. 99-112, 1986.

PEIXOTO, C. P; CÂMARA, G. M. S.; MARTINS, M. C.; MARCHIORI, L. F. S.; GUERZONI, L. A.; ATIAZZI, P. Época de semeadura e densidade de plantas de soja, I. Componentes da produção e rendimento de grãos. Scientia Agrícola, v. 57, n. 1, p. 89-96, 1999.

REUNIÃO DE PESQUISA DA SOJA DA REGIÃO SUL. Indicações técnicas para cultura da soja no Rio Grande do Sul e em Santa Catarina 2010/2011 e 2011/2012. Cruz Alta: FUNDACEP/FECOTRIGO, 2010.
RITTA NETO, A. S. Análise da conjuntura agropecuária safra 2010/11: agrometeorologia. Londrina: IAPAR, 2010.

RODRIGUES, O.; TEIXEIRA, M. C. C.; BERTAGNOLLI, P. F.; COSTENARO, E. R.; KAPP, A. C. P. Rendimento de grãos de soja: efeito do espaçamento e da densidade. Passo Fundo: Embrapa Trigo, 2011.

SCOTT A. J.; KNOTT, M. A. A cluster analysis method for grouping means in the analysis of variance. Biometrics, v. 30, n. 3, p. 507-512, 1974.

SFREDO G. J. Soja no Brasil: calagem, adubação e nutrição mineral. Londrina: Embrapa Soja (Documento Embrapa Soja), 2008.

SILVA， L. S.; MOURA, M. C. C. L; VALADARES, R. N.; SILVA, R. G.; SILVA, A. F. A. Seleção de variedades de soja em função da densidade de plantio, na microrregião de chapadinha, nordeste maranhense. Agropecuária Científica no Semi-Árido, v. 6, n. 2, p. 07-14, 2010.

TOURINO, M. C. C.; REZENDE, P. M.; SALVADOR, N. Espaçamento, densidade e uniformidade de semeadura na produtividade e características agronômicas da soja. Pesquisa Agropecuária Brasileira, v. 37, n. 8, p. 10711077, 2002.

WELLS, R. Soybean Growth to plant density: relationship among canopy photosynthesis, leaf area, and light interception. Crop Science, v.31, n. 3, p. 755-761, 1991. 